\title{
ARTICLE Social status and demographic effects of the kappa opioid receptor: a PET imaging study with a novel agonist radiotracer in healthy volunteers
}

\author{
David Matuskey ${ }^{1,2,3}$, Mark Dias ${ }^{1}$, Mika Naganawa ${ }^{1}$, Brian Pittman ${ }^{2}$, Shannan Henry ${ }^{1}$, Songye Li iD ${ }^{1}$, Hong Gao ${ }^{1}$, Jim Ropchan ${ }^{1}$, \\ Nabeel Nabulsi ${ }^{1}$, Richard E. Carson ${ }^{1}$ and Yiyun Huang ${ }^{1}$
}

\begin{abstract}
Kappa opioid receptors (KORs) have been characterized as an aversive system in the brain and implicated in social behavior in preclinical models. This work investigated the effect of social status on the KOR system in humans using positron emission tomography (PET) imaging with the novel KOR agonist radiotracer $\left[{ }^{11} \mathrm{C}\right] \mathrm{EKAP}$. Eighteen healthy participants (mean age $41.2 \pm 9.3$ ) completed the Barratt Simplified Measure of Social Status (BSMSS), an MRI and an $\left[{ }^{11} \mathrm{C}\right]$ EKAP PET scan on the High Resolution Research Tomograph. Arterial blood sampling and metabolite analysis were conducted to obtain the input function. Regions of interest were based upon an MR template and included the reward/aversion areas of the brain. The multilinear analysis-1 (MA1) method was applied to the regional time-activity curves (TACs) to calculate $\left[{ }^{11} \mathrm{C}\right] \mathrm{EKAP}$ regional volume of distribution $\left(V_{\mathrm{T}}\right)$. Mixed models and Pearson correlation coefficients were used for body mass index (BMI), gender and age, with age being dropped in subsequent analyses because of nonsignificance. An overall effect of primary ROIs $\left(F_{7,112} 7.43, p<0.0001\right)$, BSMSS score $\left(F_{1,13} 7.45\right.$, $p=0.02)$, BMI $\left(F_{1,13} 23.5, p<0.001\right)$, and gender $\left(F_{1,13} 23.75, p<0.001\right)$, but not age $\left(F_{1,13} 1.12, p=0.35\right)$ was observed. Regional $\left[{ }^{11} \mathrm{C}\right]$ EKAP $V_{\mathrm{T}}$ and BSMSS were found to be negatively correlated in the amygdala $(r=-0.69, p<0.01)$, anterior cingulate cortex $(r=-0.56, p=0.02)$, caudate $(r=-0.66, p<0.01)$, frontal cortex $(r=-0.52, p=0.04)$, hippocampus $(r=-0.60, p=0.01)$, pallidum $(r=-0.59, p=0.02)$, putamen $(r=-0.62, p=0.01)$, and ventral striatum $(r=-0.66, p<0.01)$. In secondary (non-reward) regions, correlations of $\left[{ }^{11} \mathrm{C}\right]$ EKAP $V_{\mathrm{T}}$ and BSMSS were nonsignificant with the exception of the insula. There was an inverse correlation between social status and KOR levels that was largely specific to the reward/aversion (e.g., saliency) areas of the brain. This finding suggests the KOR system may act as a mediator for the negative effects of social behaviors in humans.
\end{abstract}

Neuropsychopharmacology (2019) 44:1714-1719; https://doi.org/10.1038/s41386-019-0379-7

\section{INTRODUCTION}

Kappa opioid receptors (KORs) are the most abundant opioid receptors in the brain [1] with widespread distribution in areas highly linked to stress and reward [2-4]. Unlike the reinforcing $\mathrm{mu}(\mathrm{MOR})$ and delta (DOR) opioid receptors [1], KOR has high selectivity for endogenous dynorphins (as opposed to enkephalins) [5] and stimulation of KORs are aversive, sometimes referred as an "anti-reward" or stress system [6, 7]. The stimulation of KOR can also decrease dopamine release in the brain and therefore is a counterbalance to reinforcing properties of MOR, DOR, and dopamine $[8,9]$.

Multiple lines of evidence implicate KOR activity during stress (mediated by dynorphins) [10-13] and in maintenance of addiction through a negative reinforcement cycle of dysphoria, irritability, anxiety, anhedonia, malaise, emotional pain, and loss of motivation for natural rewards when abstinent [7, 14-16]. Recent findings have suggested a major component of natural rewards, social experiences, are also affected by $\operatorname{KORs}[17,18]$. KOR activation influences social behavior in rodents, decreasing social play while antagonism appears to reduce animal reactions to distressing social stimuli $[17,19,20]$. Mice given a KOR antagonist, or lacking a gene for dynorphin (i.e., Pdyn), did not show a typical defeated posture after exposure to repeated social defeats compared with placebo animals [21]. In the nucleus accumbens, an area integral to rewards, KOR-mediated social aversion in prairie voles [22], social status in starlings [23], and in rats there was an upregulation with social isolation [12]. Susceptible and resilient animals have also shown different expression levels of dynorphin mRNA in response to social stressors [24, 25], although differences have also been reported in this region and others [26].

The current work focuses on translating findings from animal studies implicating the KOR in social phenomena into humans by using positron emission topography (PET) imaging with the novel KOR agonist tracer $\left[{ }^{11} \mathrm{C}\right]$ EKAP [27]. This provides the first in vivo examination in humans of the relationship between KOR and social status.

\section{PARTICIPANTS AND METHODS}

\section{Participants}

This study was performed under protocols approved by the Yale Human Investigation Committee, Yale University Radiation Safety

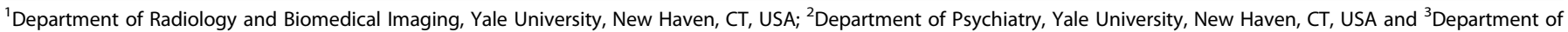
Neurology, Yale University, New Haven, CT, USA

Correspondence: David Matuskey (david.matuskey@yale.edu)

Received: 21 November 2018 Revised: 26 February 2019 Accepted: 22 March 2019

Published online: 30 March 2019 
Committee, Yale-New Haven Hospital (YNHH) Radiation Safety Committee, and Yale MRI Safety Committee. Eighteen healthy subjects without a history of psychiatric disorders or substance abuse were studied. Other exclusion criteria were current or past serious medical or neurological illness (e.g., history of head injury with loss of consciousness), current pregnancy (as documented by pregnancy testing at screening and on the day of the PET imaging study), breast feeding, or contraindications to magnetic resonance imaging (MRI). Subject eligibility was confirmed by comprehensive medical and psychiatric histories, physical examination, neurological and mental status exam, routine laboratory studies, electrocardiogram, and semi-structured [28] or structured clinical interview [29].

Once eligible, subjects completed the Barratt Simplified Measure of Social Status (BSMSS) [30]. The BSMSS has been used in previous work with PET [31,32] and is a comprehensive and updated measure of social status based on the Hollingshead index [33]. The BSMSS generates a single comprehensive total score of social status taking into account the education and occupation of the participants, their parents, and their spouse. The total score of the BSMSS was used in the analyses and it is weighted to favor the scores of the research participants and significant others over that of the parents. All screening records (e.g., occupation and education) on intake were reviewed to confirm an accurate BSMSS report.

Participants were recruited from the greater New Haven area by advertisement, word of mouth, and referral. Informed consent was obtained from all participants after a thorough explanation of the study procedures.

Radiochemistry, scanning, and imaging procedures

$\left[{ }^{11} \mathrm{C}\right]$ EKAP was prepared as previously reported $[27,34] .{ }^{11} \mathrm{C}$-EKAP displays faster kinetics and better test-retest reproducibility than the first-generation KOR agonist radiotracer ${ }^{11} \mathrm{C}-$ GR103545 (known as ${ }^{11} \mathrm{C}$-MKAP at our center), and good specific binding signals in vivo [35]. Average (SD) injected mass dose was $0.014(0.004) \mu \mathrm{g} / \mathrm{kg}$ and specific activity was $261.8(111) \mathrm{MBq} / \mathrm{nmol}$ at the time of injection.

All subjects received a structural MRI scan on a 3-T Trio system (Siemens Medical Solutions, Malvern, Pennsylvania) with a circularly polarized head coil for purposes of excluding individuals with structural abnormalities and anatomically co-registering with the PET images. The dimension and voxel size of MR images were $256 \times 256 \times 176$ voxels and $0.98 \times 0.98 \times 1.0 \mathrm{~mm}^{3}$, respectively.

Each subject then received a 120 min PET scan with $\left[{ }^{11} \mathrm{C}\right]$ EKAP on the High-Resolution Research Tomograph (HRRT) (Siemens/CTI, Knoxville, TN, USA) with 207 slices (1.2 mm slice separation) and a reconstructed image resolution of $\sim 3 \mathrm{~mm}$. A transmission scan with a ${ }^{137} \mathrm{Cs}$ point source was obtained for attenuation correction before the emission scan.

Motion correction was based on an optical detector (Vicra, NDI Systems, Waterloo, Ontario, Canada). Dynamic PET scan data were reconstructed with all corrections (attenuation; normalization; scatter; randoms; deadtime and motion), using the MOLAR algorithm [36] with the following frame timing: $6 \times 30 \mathrm{~s} ; 3 \times 1 \mathrm{~min}$; $2 \times 2 \mathrm{~min} ; 22 \times 5 \mathrm{~min}$.

A summed image (0-10 min after injection) was created from the motion-corrected PET data and registered to the subject's MR image, which in turn was nonlinearly registered to a MR template (Montreal Neurological Institute space). All transformations were performed with Bioimagesuite (version 2.5; http://www. bioimagesuite.com).

Primary regions of interest (ROIs) included the reward/aversion areas of the amygdala, anterior cingulate cortex (ACC), caudate, frontal cortex, hippocampus, pallidum, putamen, and ventral striatum (VS) and were based on the Anatomical Automatic Labeling (AAL) template delineated on MR with the exception of a hand-drawn VS template as done in prior work [37, 38]. A post-hoc test was also done in frontal cortex subdivisions including the ventromedial prefrontal cortex (vmPFC), orbitofrontal cortex (OFC) and dorsolateral prefrontal cortex (dIPFC). Secondary areas included non-reward areas of the thalamus, insula and parietal, temporal and occipital cortical regions. The cerebellum had relatively low KOR binding (mean $V_{\mathrm{T}}=5.7$ ), was not significant and excluded from further analysis.

Arterial blood sampling and metabolite analysis were conducted during each PET scan to obtain the arterial input function. The multilinear analysis-1 (MA1) method was applied to the regional time-activity curves (TACs) to calculate $\left[{ }^{11} \mathrm{C}\right] \mathrm{EKAP}$ volume of distribution $\left(V_{T}\right)$ using the metabolite-corrected input function.

\section{Statistical considerations}

All outcomes were summarized descriptively and assessed for normality prior to analysis using normal probability plots and Kolmogorov test statistics. All outcomes were approximately normal. Linear mixed models were used to examine the independent and joint effects of group (between-subject factor) and region of interest (within-subject factor) on $V_{T}$ values. Within-subject correlations were accounted for by fitting three variancecovariance structures to the data (unstructured, compound symmetry, and heterogeneous compound symmetry) with an unstructured form fitting the data best according to the Bayesian Information Criterion (BIC). Gender, age, body mass index (BMI), and injection mass dose were considered as covariates in the above models but age and injection dose were not significant and dropped for parsimony. Potential associations between BSMSS scores, clinical characteristics, and demographics with ROls were estimated using Pearson correlation coefficients and subsequently adjusted for BMl and gender due to known effects of these variables on KOR [39]. Given the interrelation of the primary ROls, a Hommel-adjusted $p$-value was selected. All analyses were considered significant at the two-tailed $a<0.05$ threshold and were conducted using SAS, version 19 (Armonk, NY).

\section{RESULTS}

Means and standard deviations of demographic and clinical characteristics for the participants are shown in Table 1. All subjects were nonsmokers and had no or minimal current weekly alcohol consumption (up to three drinks per week).

The results of the primary mixed model showed significance for an overall effect of primary ROIs $\left(F_{7,112} 7.43, p<0.0001\right)$, BSMSS score $\left(F_{1,13} 7.45, p=0.02\right)$, BMI $\left(F_{1,13} 23.5, p<0.001\right)$, and gender $\left(F_{1,13} 23.75, p<0.001\right)$, but not a significant social status-ROI interaction $\left(F_{1,13} 1.14, p=0.34\right)$ or overall effect of age $\left(F_{1,13} 1.12\right.$, $p=0.35$ ). Age was subsequently dropped from further model analyses. BSMSS was not significantly different between genders (mean total score was 58 for males and 61 for females). BSMSS was also not correlated with age $(r=-0.12, p=0.96)$ or BMI $(r=-0.15, p=0.55)$; correlations for both age and BMI and all ROIs are in Table 2. Gender differences for ROls are also presented in Table 3.

Table 4 presents average $V_{\mathrm{T}}$ values (with standard deviations) for the primary ROls along with correlations after being adjusted for BMI and gender with uncorrected $p$-values, the slope of the BSMSS and $V_{\mathrm{T}}$ values corrected for multiple comparisons. Individual data points are shown in Fig. 1 for BSMSS total score

\begin{tabular}{|c|c|c|c|c|}
\hline Age & Gender & Race & BMI $\left(k g / m^{2}\right)$ & BSMSS \\
\hline $\begin{array}{l}35(10) ; \text { range } \\
20-51\end{array}$ & $9 \mathrm{M}, 9 \mathrm{~F}$ & $\begin{array}{l}8 \mathrm{C}, 6 \mathrm{AA} \\
30,1 \mathrm{H}\end{array}$ & $\begin{array}{l}26(3) ; \text { range } \\
20-31\end{array}$ & $\begin{array}{l}60 \text { (18); range } \\
22-87\end{array}$ \\
\hline
\end{tabular}


Table 2. Age and BMI correlations with all ROls

\begin{tabular}{lllll}
\hline ROI & Age & $p$-Value & BMI $\left(\mathrm{kg} / \mathrm{m}^{2}\right)$ & $p$-Value \\
\hline Amygdala & -0.2975 & 0.23 & -0.5438 & 0.02 \\
ACC & -0.2478 & 0.32 & -0.4753 & 0.05 \\
Caudate & -0.4399 & 0.07 & -0.6944 & $<0.001$ \\
Frontal cortex & -0.3904 & 0.11 & -0.7266 & $<0.001$ \\
Hippocampus & -0.3067 & 0.22 & -0.6300 & $<0.01$ \\
Occipital cortex & -0.4074 & 0.09 & -0.7156 & $<0.001$ \\
Pallidum & -0.3485 & 0.16 & -0.6391 & $<0.01$ \\
Parietal cortex & -0.4422 & 0.07 & -0.6986 & $<0.01$ \\
Putamen & -0.4044 & 0.10 & -0.7362 & $<0.001$ \\
Temporal cortex & -0.3854 & 0.11 & -0.7400 & $<0.001$ \\
Thalamus & -0.4137 & 0.09 & -0.7055 & $<0.01$ \\
VS & -0.4096 & 0.09 & -0.6607 & $<0.01$ \\
\hline
\end{tabular}

The $p$-values are uncorrected for multiple comparisons

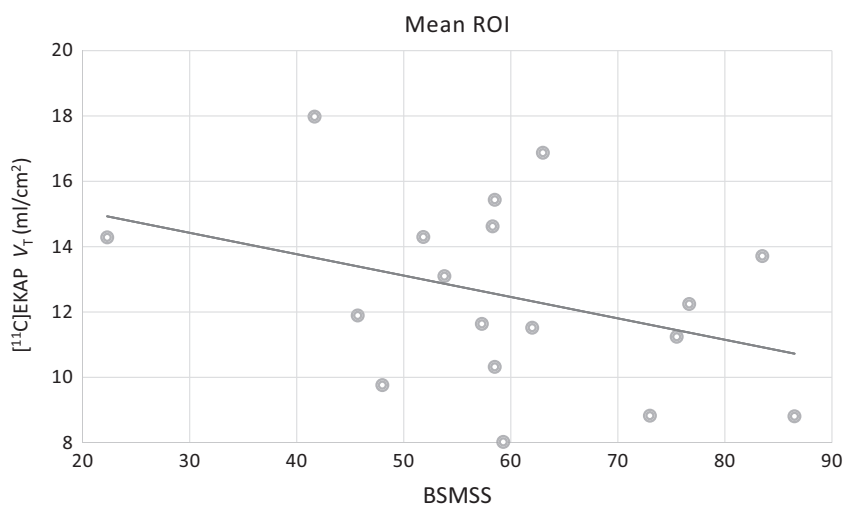

Fig. 1 Mean region of interest (ROI) includes all the primary ROls along with the total Barratt Simplified Measure of Social Status (BSMSS) score. Values shown are unadjusted for body mass index (BMI) and gender

Table 3. Gender differences between ROls

\begin{tabular}{|c|c|c|c|c|c|c|c|c|c|}
\hline ACC & 9 & 13.4 & 2.6 & 9 & 16.0 & 3.2 & 16 & -1.89 & 0.08 \\
\hline Caudate & 9 & 6.7 & 1.5 & 9 & 9.2 & 1.8 & 16 & -3.26 & $<0.01$ \\
\hline Frontal cortex & 9 & 8.6 & 1.5 & 9 & 11.0 & 1.7 & 16 & -3.26 & $<0.01$ \\
\hline Insula & 9 & 13.0 & 2.6 & 9 & 16.9 & 2.7 & 16 & -3.09 & 0.01 \\
\hline Occipital cortex & 9 & 7.3 & 1.3 & 9 & 9.3 & 1.1 & 16 & -3.48 & $<0.01$ \\
\hline Pallidum & 9 & 10.4 & 2.0 & 9 & 14.2 & 3.3 & 16 & -2.98 & 0.01 \\
\hline Parietal cortex & 9 & 7.6 & 1.3 & 9 & 9.7 & 1.3 & 16 & -3.46 & $<0.01$ \\
\hline Putamen & 9 & 8.7 & 1.4 & 9 & 11.4 & 2.0 & 16 & -3.38 & $<0.01$ \\
\hline Temporal cortex & 9 & 9.3 & 1.7 & 9 & 11.7 & 1.7 & 16 & -3.12 & $<0.01$ \\
\hline
\end{tabular}

Table 4. $V_{\mathrm{T}}$ values are mean (SD) and shown with correlation with BSMSS total score after being adjusted for BMI and gender

\begin{tabular}{llllll}
\hline $\begin{array}{l}\text { Region of } \\
\text { interest (ROI) }\end{array}$ & $\begin{array}{l}V_{\mathrm{T}} \text { mean } \\
\text { (SD) }\end{array}$ & Pearson $R$ & $p$-Value & Slope & $\begin{array}{l}p \text {-Value } \\
\text { (Hommel) }\end{array}$ \\
\hline Amygdala & $22.4(5.9)$ & -0.69 & $<0.01$ & -0.1963 & 0.04 \\
ACC & $14.7(3.1)$ & -0.56 & 0.02 & -0.0892 & 0.04 \\
Caudate & $7.9(2.1)$ & -0.66 & $<0.01$ & -0.0493 & 0.03 \\
Frontal cortex & $9.8(2.0)$ & -0.52 & 0.04 & -0.0353 & 0.04 \\
Hippocampus & $8.7(2.0)$ & -0.60 & 0.01 & -0.0579 & 0.04 \\
Pallidum & $12.3(3.3)$ & -0.59 & 0.02 & -0.0733 & 0.04 \\
Putamen & $10.1(2.1)$ & -0.62 & 0.01 & -0.0432 & 0.04 \\
VS & $14.0(3.4)$ & -0.66 & $<0.01$ & -0.0817 & 0.04 \\
\hline
\end{tabular}

The slope of the BSMSS value is also shown in each primary region along with corrected $p$-values and an averaged unadjusted value of the primary ROIs. Individual ROls are shown in supplemental Figure S1. A post-hoc test of frontal cortex subdivisions showed correlations in the $\operatorname{vmPFC}(r=-0.55, p=0.03)$, OFC $(r=-0.48, p=0.06)$, and dIPFC $(r=-0.52, p=0.04)$.

The secondary non-reward areas were nonsignificant with BSMSS score in the thalamus $(r=-0.32, p=0.22)$, parietal $(r=-0.36, p=0.18)$, temporal $(r=-0.47, p=0.07)$, and occipital cortical regions $(r=-0.39, p=0.13)$, with the exception of the insula $(r=-0.58, p=0.02)$. These values were adjusted for BMI and gender, but not multiple comparisons. Representative images of individuals with the highest and lowest BSMSS scores are shown in Fig. 2 for comparison purposes.

\section{DISCUSSION}

The current study is the first to directly investigate the relationship between the KOR system and social status in humans. Using a novel KOR tracer, we found an inverse correlation between social 


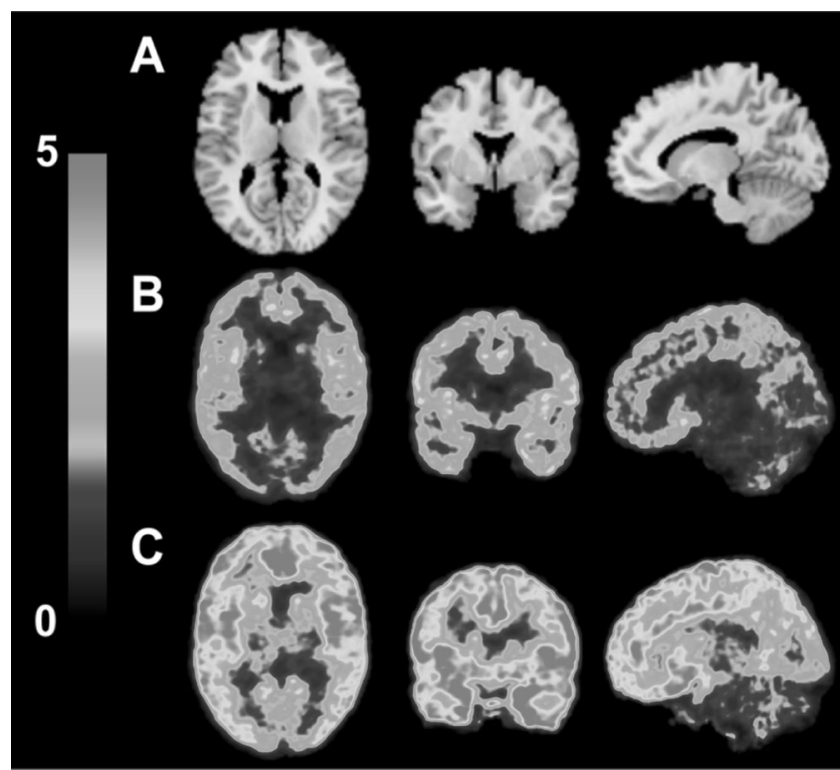

Fig. 2 Template $M R$ (a) and co-registered positron emission tomography (PET) images summed from 30 to 90 min after $11 \mathrm{C}$ EKAP injection for high (b) and low (c) Barratt Simplified Measure of Social Status (BSMSS) score individuals. Activity is expressed as SUV [concentration/(injected dose/body weight)]

status and KOR levels that was largely specific to the primary ROls. This relationship gives evidence that lower social status in humans is associated with increased KOR levels, which is important because these regions are implicated in the "anti-reward"/stress systems and are at least partially mediated by dynorphins/KOR in the brain $[6,7]$. The robust $V_{\mathrm{T}}$ values $(7.9-22.4)$ also provide support for the importance of KOR in these areas.

With lower social status viewed as a stressor, our findings of increased KOR levels largely fit with the extant animal literature on social processes, and more exactly, with the lone study on social status and KOR (in male European starlets) [23]. Pair bonding, an important social behavior, has been more studied and found to be influenced by KOR in monogamous animals such as titi monkeys and prairie voles [40-42]. Factors such as these could presumably influence social status across species. In humans, there is less evidence of KOR impacted by social processes, but indirect suggestion with pharmacologic studies is available. One double-blind, placebo-controlled study in 48 healthy controls found evidence that low-dose buprenorphine, a KOR antagonist/ MOR agonist, diminishes the response to social stress in behavioral tasks [43]. Naltrexone, a nonspecific opioid antagonist, has also been found to alter emotional reactions to social stimuli, with the authors speculating that increased attention to emotional expression, slowed identification of sadness and fear, and decreased ratings of arousal for social and nonsocial emotional scenes were more consistent with KOR rather than MOR antagonist effects [44]. Both of these studies were not designed to tease out specific opioid receptor contributions, but more recent post-mortem work has attempted to do this in childhood abuse and control subjects. Opioid receptors (MOR, KOR, and DOR) were examined with real-time polymerase chain reaction in the ACC, mediodorsal thalamus, and anterior insula. Interestingly, only the KOR was found to be significantly different in controls, with downregulation in the anterior insula. It is not clear if these results are different from our own due to the type of stress or methodological differences [18]. Of note, the insula was included as a secondary region in the current analysis with similar findings as the primary regions, showing that anatomical variation is likely not the cause. A clinical PET imaging study at Yale in trauma- exposed subjects with no opioid use dependency showed a negative correlation between loss symptoms (i.e., emotional numbing, depression, and anxiety) and KOR availability in an composite brain region [45], congruent with our current findings and indicating that stress-related phenomena (either by social or trauma mechanisms) seem to be consistent in regards to the $\mathrm{KOR}$ in vivo.

The current findings do contrast, however, with previous work showing a positive correlation between striatal $D_{2 / 3} R$ availability and social status in humans using the non-selective $D_{2 / 3} R$ antagonist $\left[{ }^{11} \mathrm{C}\right]$ raclopride $[32,46]$. Our previous work showed a negative correlation in the substantia nigra/ventral tegmental area (SN/VTA) with the $D_{3} R$ preferring $D_{2 / 3} R$ agonist tracer $\left[{ }^{11} C\right](+)$ PHNO [31], which is actually congruent with the $\left[{ }^{11} \mathrm{C}\right.$ raclopride data considering the converse relationships of striatal $D_{2} R$ and $S N /$ VTA $D_{3} R$ in other populations $[38,47-49]$. Taken together, these studies in humans, as well as non-human primate studies [50] suggest an intricate relationship between dopamine function and social behavior where dopamine release and $D_{2 / 3} R$ may maintain social hierarchy [51]. The KOR system may be acting in opposing ways to the dopamine system as a mediator for the negative effects of social behaviors in humans. This possibility would have a direct mechanism to support it as physiologically KOR is located presynaptically on dopamine terminals and can suppress dopamine release in the reward areas of the brain [12, 52-54].

Like dopamine, MOR is also rewarding and has been implicated in social behavior in humans [55-57]. Imaging studies focused on social rejection indicate both increased and decreased MOR receptor availability with positive and negative social cues in healthy individuals [58]. The abundance of supporting evidence from animal literature $[59,60]$ makes it likely that MOR and dopamine systems are working in concert for the positive reinforcement of social behaviors, contrasting with the KOR system.

Previous work with an antagonist KOR tracer at Yale $\left(\left[{ }^{11} \mathrm{C}\right]\right.$ LY2795050) has shown gender differences with males having higher $V_{T}$ than females across most brain regions [39]. The current findings are in the opposite direction (higher $V_{T}$ in females than males) and given the similar methods a probable rationale for this difference is the use of a KOR agonist vs. antagonist tracer as the former might only detect a high affinity state while the latter could detect total KOR expression levels. There is literature to support possible agonist/antagonist differences, with females showing stronger clinical responses to KOR agonists than males [61-63]. Thus, in addition to showing a possible mechanism of gender-specific responses to pain and social aversion [20], these findings also highlight important considerations for the use of KOR agonist vs. antagonist tracers in future studies.

Statistically significant findings were also found with regards to $\mathrm{BMI}$, with negative correlations (uncorrected) found in all regions with $\left[{ }^{11} \mathrm{C}\right]$ EKAP $V_{\mathrm{T}}$. While this is the first human report of a relationship between KOR and BMI, the KOR system has been implicated in eating disorders and obesity [64]. Higher concentrations of KOR have been found in obese compared with lean mice [65], and it's unclear why this differs from our findings although species and the selection of an agonist tracer likely have a role. In fact, KOR agonists and antagonists have both been found to augment eating behaviors with specific effects depending on species and paradigms $[64,66,67]$. Future studies could see if the current findings extend into morbid obesity and possibly beyond as KOR binding has been known to be altered in diabetic rats [68].

We did not observe any age effects in this cohort. This seems somewhat surprising considering that age effects on other neurotransmitter systems have been found by us and others with PET imaging [69-72], but the literature is noticeably quiet as to whether KORs are susceptible to aging with only a sole autoradiographic study of aging in guinea pigs finding 
large decreases (18-42\%) in cortical areas of 6- to 36-month-old animals [73].

Limitations of the current study include not being able to distinguish dynorphin receptor occupancy vs. KOR changes, which can possibly confound results. The difficulty of reliably interpreting endogenous ligand vs. receptors is commonplace in PET imaging as radioligand binding can only occur in available receptors. Further understanding can take place by depletion studies (e.g., AMPT for dopamine tracers), a technique not currently available for the KOR/dynorphin system. Another limitation is the use of the BSMSS as a measure of social status as several occupations listed are obsolete (e.g., typist) or not reflective of current professions (e.g., webmaster or software engineer, etc.). Nevertheless, along with others, we have shown important relationships previously with this measure [31, 32]. In females, the menstrual cycle was not controlled for, and while evidence has been shown that this has little to no effect on dynorphins in macaques [74], it could also be considered a limitation in the current work. Finally, age and BMI range are somewhat limited and therefore not conclusive.

Implications of this work can be far reaching if this is confirmed as a mechanism of socioeconomic stresses not only because of the central importance in understanding the physiological effects of society, but also because of the implications in psychiatric and addictive disorders. In fact, KOR pharmacologic treatments are being investigated in several conditions including major depressive disorder, anxiety spectrum disorders, substance use disorders, and clinical elements of stress $[75,76]$. The effective management of social stressors in these conditions have long plagued us clinically and the KOR system could be of high utility in this regard.

\section{FUNDING AND DISCLOSURE}

We would like to thank the staff of the Yale PET Center and the Yale Magnetic Resonance Research Center (MRRC). This work was supported by NIH grants R21MH092664 and R33MH092664 (to $\mathrm{YH}$ ). The authors declare no competing interests. The contents of this publication are solely the responsibility of the authors and do not necessarily represent the official view of $\mathrm{NIH}$.

\section{ADDITIONAL INFORMATION}

Supplementary Information accompanies this paper at (https://doi.org/10.1038/ s41386-019-0379-7).

Publisher's note: Springer Nature remains neutral with regard to jurisdictional claims in published maps and institutional affiliations.

\section{REFERENCES}

1. Minami M, Satoh M. Molecular biology of the opioid receptors: structures, functions and distributions. Neurosci Res. 1995;23:121-45.

2. Mansour A, Fox CA, Thompson RC, Akil H, Watson SJ. Mu-Opioid receptor mRNA expression in the rat CNS: comparison to mu-receptor binding. Brain Res. 1994;643:245-65.

3. Simonin F, Gaveriaux-Ruff C, Befort K, Matthes H, Lannes B, Micheletti G, et al. Kappa-opioid receptor in humans: cDNA and genomic cloning, chromosomal assignment, functional expression, pharmacology, and expression pattern in the central nervous system. Proc Natl Acad Sci USA. 1995;92:7006-10.

4. Helal MA, Habib ES, Chittiboyina AG. Selective kappa opioid antagonists for treatment of addiction, are we there yet? Eur J Med Chem. 2017;141:632-47.

5. Akil H, Owens C, Gutstein H, Taylor L, Curran E, Watson S. Endogenous opioids: overview and current issues. Drug Alcohol Depend. 1998;51:127-40.

6. Koob GF, Mason BJ. Existing and future drugs for the treatment of the dark side of addiction. Annu Rev Pharmacol Toxicol. 2016;56:299-322.

7. Koob GF, Le Moal M. Plasticity of reward neurocircuitry and the 'dark side' of drug addiction. Nat Neurosci. 2005;8:1442-4.

8. Wee S, Koob GF. The role of the dynorphin-kappa opioid system in the reinforcing effects of drugs of abuse. Psychopharmacology (Berl). 2010;210:121-35.
9. Di Chiara G, Imperato A. Opposite effects of mu and kappa opiate agonists on dopamine release in the nucleus accumbens and in the dorsal caudate of freely moving rats. J Pharmacol Exp Ther. 1988;244:1067-80.

10. Bruchas MR, Land BB, Chavkin C. The dynorphin/kappa opioid system as a modulator of stress-induced and pro-addictive behaviors. Brain Res. 2010;1314: 44-55.

11. Land BB, Bruchas MR, Lemos JC, Xu M, Melief EJ, Chavkin C. The dysphoric component of stress is encoded by activation of the dynorphin kappa-opioid system. J Neurosci. 2008;28:407-14.

12. Karkhanis AN, Rose JH, Weiner JL, Jones SR. Early-life social isolation stress increases kappa opioid receptor responsiveness and downregulates the dopamine system. Neuropsychopharmacology. 2016;41:2263-74.

13. Nabeshima T, Kamei H, Matsuno K, Kameyama T. Conditioned suppression and opioid kappa receptor in mice. J Pharmacobiodyn. 1986;9:74-80.

14. Koob GF. The dark side of emotion: the addiction perspective. Eur J Pharmacol. 2015;753:73-87.

15. Chavkin C, Shoemaker WJ, McGinty JF, Bayon A, Bloom FE. Characterization of the prodynorphin and proenkephalin neuropeptide systems in rat hippocampus. J Neurosci. 1985;5:808-16.

16. Koob GF, Le Moal M. Addiction and the brain antireward system. Annu Rev Psychol. 2008;59:29-53.

17. Lalanne L, Ayranci G, Kieffer BL, Lutz PE. The kappa opioid receptor: from addiction to depression, and back. Front Psychiatry. 2014;5:170.

18. Lutz PE, Gross JA, Dhir SK, Maussion G, Yang J, Bramoulle A, et al. Epigenetic regulation of the kappa opioid receptor by child abuse. Biol Psychiatry 2017, 84:751-61.

19. Vanderschuren $\sqcup$, Niesink RJ, Spruijt BM, Van Ree JM. Mu- and kappa-opioid receptor-mediated opioid effects on social play in juvenile rats. Eur J Pharmacol. 1995;276:257-66.

20. Robles CF, McMackin MZ, Campi KL, Doig IE, Takahashi EY, Pride MC, et al. Effects of kappa opioid receptors on conditioned place aversion and social interaction in males and females. Behav Brain Res. 2014;262:84-93.

21. McLaughlin JP, Li S, Valdez J, Chavkin TA, Chavkin C. Social defeat stress-induced behavioral responses are mediated by the endogenous kappa opioid system. Neuropsychopharmacology. 2006;31:1241-8.

22. Resendez SL, Kuhnmuench M, Krzywosinski T, Aragona BJ. Kappa-opioid receptors within the nucleus accumbens shell mediate pair bond maintenance. J Neurosci. 2012;32:6771-84.

23. Riters LV, Cordes MA, Stevenson SA. Prodynorphin and kappa opioid receptor mRNA expression in the brain relates to social status and behavior in male European starlings. Behav Brain Res. 2017;320:37-47.

24. Berube P, Laforest S, Bhatnagar S, Drolet G. Enkephalin and dynorphin mRNA expression are associated with resilience or vulnerability to chronic social defeat stress. Physiol Behav. 2013;122:237-45.

25. Donahue RJ, Landino SM, Golden SA, Carroll FI, Russo SJ, Carlezon WA Jr. Effects of acute and chronic social defeat stress are differentially mediated by the dynorphin/kappa-opioid receptor system. Behav Pharmacol. 2015; 26:654-63.

26. Nocjar C, Zhang J, Feng P, Panksepp J. The social defeat animal model of depression shows diminished levels of orexin in mesocortical regions of the dopamine system, and of dynorphin and orexin in the hypothalamus. Neuroscience. 2012;218:138-53.

27. Li S, Zheng MQ, Naganawa M, Kim S, Gao H, Kapinos M, et al. Development and in vivo evaluation of a novel kappa opioid receptor agonist as PET radiotracer with superior imaging characteristics. J Nucl Med. 2019.

28. Sheehan DV, Lecrubier Y, Sheehan KH, Amorim P, Janavs J, Weiller E, et al. The Mini-International Neuropsychiatric Interview (M.I.N.I.): the development and validation of a structured diagnostic psychiatric interview for DSM-IV and ICD-10. J Clin Psychiatry. 1998;59(Suppl 20):22-33.

29. American Psychiatric Association., American Psychiatric Association. Task Force on DSM-IV. Diagnostic and statistical manual of mental disorders: DSM-IV-TR. 4th ed. Washington, DC: American Psychiatric Association; 2000.

30. Barratt W. The Barratt Simplified Measure of Social Status (BSMSS) measuring SES. 2006. Available from: https://www.wbarratt.indstate.edu/socialclass/Barratt Simplifed Measure of Social Status.pdf

31. Matuskey D, Gaiser EC, Gallezot JD, Angarita GA, Pittman B, Nabulsi N, et al. A preliminary study of dopamine D2/3 receptor availability and social status in healthy and cocaine dependent humans imaged with $[(11) \mathrm{C}](+) \mathrm{PHNO}$. Drug Alcohol Depend. 2015;154:167-73.

32. Martinez D, Orlowska D, Narendran R, Slifstein M, Liu F, Kumar D, et al. Dopamine type $2 / 3$ receptor availability in the striatum and social status in human volunteers. Biol Psychiatry. 2010;67:275-8.

33. Hollingshead AB. Four factor index of social status. New Haven, CT: Department of Sociology, Yale University; 1975. 
34. Li SZM, Lin SF, Kim SJ, Naganawa M, Carson R, Huang, Y, et al. Development and in vivo evaluation of a novel kappa opioid receptor agonist as PET radiotracer with superior imaging characteristics. J Nucl Med. 2014;1112:s55.

35. Naganawa M, Jacobsen LK, Zheng MQ, Lin SF, Banerjee A, Byon W, et al. Evaluation of the agonist PET radioligand $\left[{ }^{11} \mathrm{C}\right] \mathrm{GR} 103545$ to image kappa opioid receptor in humans: kinetic model selection, test-retest reproducibility and receptor occupancy by the antagonist PF-04455242. Neuroimage. 2014;99:69-79.

36. Carson RE, Barker, WC, Liow, J-S, Johnson, CA. Design of a motioncompensation OSEM list-mode algorithm for resolution-recovery reconstruction of the HRRT. In: Conference Record, IEEE Nuclear Science Symposium and Medical Imaging Conference, Portland, OR. pp. 3281-5; 2003.

37. Tzourio-Mazoyer N, Landeau B, Papathanassiou D, Crivello F, Etard O, Delcroix N et al. Automated anatomical labeling of activations in SPM using a macroscopic anatomical parcellation of the MNI MRI single-subject brain. Neuroimage. 2002; 15:273-89.

38. Matuskey D, Gallezot JD, Pittman B, Williams W, Wanyiri J, Gaiser E, et al. Dopamine $D(3)$ receptor alterations in cocaine-dependent humans imaged with [(1)(1)C](+)PHNO. Drug Alcohol Depend. 2014;139:100-5.

39. Vijay A, Wang S, Worhunsky P, Zheng MQ, Nabulsi N, Ropchan J, et al. PET imaging reveals sex differences in kappa opioid receptor availability in humans, in vivo. Am J Nucl Med Mol Imaging. 2016;6:205-14.

40. Ragen BJ, Maninger N, Mendoza SP, Bales KL. The effects of morphine, naloxone, and kappa opioid manipulation on endocrine functioning and social behavior in monogamous titi monkeys (Callicebus cupreus). Neuroscience. 2015;287:32-42.

41. Ragen BJ, Freeman SM, Laredo SA, Mendoza SP, Bales KL. Mu and kappa opioid receptor distribution in the monogamous titi monkey (Callicebus cupreus): implications for social behavior and endocrine functioning. Neuroscience. 2015;290:421-34.

42. Martin TJ, Sexton T, Kim SA, Severino AL, Peters CM, Young LJ, et al. Regional differences in mu and kappa opioid receptor $\mathrm{G}$-protein activation in brain in male and female prairie voles. Neuroscience. 2015;311:422-9.

43. Bershad AK, Jaffe JH, Childs E, de Wit H. Opioid partial agonist buprenorphine dampens responses to psychosocial stress in humans. Psychoneuroendocrinology. 2015;52:281-8.

44. Wardle MC, Bershad AK, de Wit $\mathrm{H}$. Naltrexone alters the processing of social and emotional stimuli in healthy adults. Soc Neurosci. 2016;11:579-91.

45. Pietrzak RH, Naganawa $M$, Huang $Y$, Corsi-Travali S, Zheng MQ, Stein MB, et al. Association of in vivo kappa-opioid receptor availability and the transdiagnostic dimensional expression of trauma-related psychopathology. JAMA Psychiatry. 2014;71:1262-70.

46. Wiers CE, Shokri-Kojori E, Cabrera E, Cunningham S, Wong C, Tomasi D, et al. Socioeconomic status is associated with striatal dopamine D2/D3 receptors in healthy volunteers but not in cocaine abusers. Neurosci Lett. 2016;617:27-31.

47. Worhunsky PD, Matuskey D, Gallezot JD, Gaiser EC, Nabulsi N, Angarita GA, et al. Regional and source-based patterns of $[(11) \mathrm{C}]-(+)-P H N O$ binding potential reveal concurrent alterations in dopamine D2 and D3 receptor availability in cocaineuse disorder. Neuroimage. 2017;148:343-51.

48. Gaiser EC, Gallezot JD, Worhunsky PD, Jastreboff AM, Pittman B, Kantrovitz L, et al. Elevated dopamine D2/3 receptor availability in obese individuals: a PET imaging study with $[(11) C](+) P H N O$. Neuropsychopharmacology. 2016;41:3042-50.

49. Caravaggio F, Ku Chung J, Plitman E, Boileau I, Gerretsen P, Kim J, et al The relationship between subcortical brain volume and striatal dopamine D2/3 receptor availability in healthy humans assessed with [(11) C]-raclopride and [(11) C]-(+)-PHNO PET. Hum Brain Mapp. 2017;38:5519-34.

50. Morgan D, Grant KA, Gage HD, Mach RH, Kaplan JR, Prioleau O, et al. Social dominance in monkeys: dopamine D2 receptors and cocaine self-administration. Nat Neurosci. 2002;5:169-74.

51. Yamaguchi $Y$, Lee $Y A$, Kato $A$, Jas $E$, Goto $Y$. The roles of dopamine $D 2$ receptor in the social hierarchy of rodents and primates. Sci Rep. 2017;7:43348.

52. Werling LL, Frattali A, Portoghese PS, Takemori AE, Cox BM. Kappa receptor regulation of dopamine release from striatum and cortex of rats and guinea pigs. J Pharmacol Exp Ther. 1988;246:282-6.

53. Svingos AL, Chavkin C, Colago EE, Pickel VM. Major coexpression of kappa-opioid receptors and the dopamine transporter in nucleus accumbens axonal profiles. Synapse. 2001;42:185-92.

54. Ebner SR, Roitman MF, Potter DN, Rachlin AB, Chartoff EH. Depressive-like effects of the kappa opioid receptor agonist salvinorin $A$ are associated with decreased phasic dopamine release in the nucleus accumbens. Psychopharmacology (Berl). 2010;210:241-52

55. Way BM, Taylor SE, Eisenberger NI. Variation in the mu-opioid receptor gene (OPRM1) is associated with dispositional and neural sensitivity to social rejection. Proc Natl Acad Sci USA. 2009;106:15079-84.

56. Panksepp J, Herman B, Conner R, Bishop P, Scott JP. The biology of social attachments: opiates alleviate separation distress. Biol Psychiatry. 1978;13: 607-18.

57. Trezza V, Damsteegt R, Achterberg EJ, Vanderschuren LJ. Nucleus accumbens mu-opioid receptors mediate social reward. J Neurosci. 2011;31:6362-70.

58. Hsu DT, Sanford BJ, Meyers KK, Love TM, Hazlett KE, Wang H, et al. Response of the mu-opioid system to social rejection and acceptance. Mol Psychiatry. 2013;18:1211-7.

59. Panksepp J, Herman BH, Vilberg T, Bishop P, DeEskinazi FG. Endogenous opioids and social behavior. Neurosci Biobehav Rev. 1980;4:473-87.

60. D'Amato FR, Pavone F. Modulation of nociception by social factors in rodents: contribution of the opioid system. Psychopharmacology (Berl). 2012;224: 189-200.

61. Gear RW, Miaskowski C, Gordon NC, Paul SM, Heller PH, Levine JD. The kappa opioid nalbuphine produces gender- and dose-dependent analgesia and antianalgesia in patients with postoperative pain. Pain. 1999;83:339-45.

62. Gear RW, Miaskowski C, Gordon NC, Paul SM, Heller PH, Levine JD. Kappa-opioids produce significantly greater analgesia in women than in men. Nat Med. 1996;2:1248-50.

63. Gear RW, Gordon NC, Heller PH, Paul S, Miaskowski C, Levine JD. Gender difference in analgesic response to the kappa-opioid pentazocine. Neurosci Lett. 1996;205:207-9.

64. Karkhanis A, Holleran KM, Jones SR. Dynorphin/kappa opioid receptor signaling in preclinical models of alcohol, drug, and food addiction. Int Rev Neurobiol. 2017;136:53-88.

65. Khawaja XZ, Bailey CJ, Green IC. Central mu, delta, and kappa opioid binding sites, and brain and pituitary beta-endorphin and met-enkephalin in genetically obese (ob/ob) and lean mice. Life Sci. 1989;44:1097-105.

66. Jarosz PA. The effect of kappa opioid receptor antagonism on energy expenditure in the obese Zucker rat. Biol Res Nurs. 2007;8:294-9.

67. Ferguson-Segall M, Flynn JJ, Walker J, Margules DL. Increased immunoreactive dynorphin and leu-enkephalin in posterior pituitary of obese mice (ob/ob) and super-sensitivity to drugs that act at kappa receptors. Life Sci. 1982;31: 2233-6.

68. Wolinsky TD, Carr KD, Hiller JM, Simon EJ. Chronic food restriction alters mu and kappa opioid receptor binding in the parabrachial nucleus of the rat: a quantitative autoradiographic study. Brain Res. 1996;706:333-6.

69. Radhakrishnan R, Nabulsi N, Gaiser E, Gallezot JD, Henry S, Planeta B, et al. Agerelated change in 5-HT6 receptor availability in healthy male volunteers measured with (11)C-GSK215083 PET. J Nucl Med. 2018.

70. Matuskey D, Pittman B, Planeta-Wilson B, Walderhaug E, Henry S, Gallezot JD, et al. Age effects on serotonin receptor $1 B$ as assessed by PET. J Nucl Med. 2012;53:1411-4.

71. Matuskey D, Worhunksy P, Correa E, Pittman B, Gallezot JD, Nabulsi N, et al Age-related changes in binding of the $\mathrm{D} 2 / 3$ receptor radioligand $[(11) \mathrm{C}](+) \mathrm{PHNO}$ in healthy volunteers. Neuroimage. 2016;130:241-7.

72. Moses-Kolko EL, Price JC, Shah N, Berga S, Sereika SM, Fisher PM, et al. Age, sex, and reproductive hormone effects on brain serotonin-1A and serotonin-2A receptor binding in a healthy population. Neuropsychopharmacology. 2011;36 2729-40.

73. Hiller JM, Fan LQ, Simon EJ. Age-related changes in kappa opioid receptors in the guinea-pig brain: a quantitative autoradiographic study. Neuroscience. 1992;50: 663-73.

74. Eghlidi DH, Haley GE, Noriega NC, Kohama SG, Urbanski HF. Influence of age and 17beta-estradiol on kisspeptin, neurokinin $B$, and prodynorphin gene expression in the arcuate-median eminence of female rhesus macaques. Endocrinology. 2010;151:3783-94.

75. Carlezon WA Jr., Krystal AD. Kappa-opioid antagonists for psychiatric disorders: from bench to clinical trials. Depress Anxiety. 2016;33:895-906.

76. Crowley NA, Kash TL. Kappa opioid receptor signaling in the brain: circuitry and implications for treatment. Prog Neuropsychopharmacol Biol Psychiatry. 2015;62: $51-60$. 